\title{
Neue Borkenkäfergattungen und Arten aus Afrika.
} (Col.)

\section{Von Dr. M. Hagedorn, Hamburg.}

Mit 2 Tafeln und 1 Textfigur.

Seitdem unsere afrikanischen Kolonien dem Plantagenbau zur Anzucht von Nutzgewächsen immer mehr erschlossen werden, ist man natürlich auch auf das Auftreten von Schädlingen aufmerksam geworden. Ich habe einige von diesen, die Borkenkäfer der Kaffee- und der Kautschukpflanzen, bereits zusammengestellt, um die Interessenten auf das Vorhandensein und die Bekämpfung der in Betracht kommenden Borkenkäfer hinzuweisen. Erfreulicherweise werden nun auch diese Tiere in unseren Kolonien eifrig gesammelt; es ergibt sich aus dem, was bisher hierher gelangt ist, ein ungeahnter Reichtum an neuen Gattungen und neuen Arten. Jede Sendung, die ich aus Afrika erhalten habe, birgt eine Reihe von bisher unbekannten Tieren. Damit man nun von diesen sprechen könne, ist es nötig, sie zu benennen. Wenn auch zunächst nur die Systematik dadurch bereichert wird, so wird allmählich auch die Biologie, die Erforschung der Lebensweise und dadurch das Auffinden von Mitteln zur Bekämpfung der Schädlinge gefördert werden.

\section{Dactylipalpus floccosus n. sp.}

Oblongus, subcylindricus, niger, pilis flavo-auratis longioribus in elytris floccosis adspersus, antennis tarsisque rufescentibus, rostro lato punctato et piloso, linea mediana laevi et lata ornatus; oculis subtus contiguis, in fronte plana discretis. Prothorace transverso subquadrato longitudine duplo latiori, densissime granulato-punctato, piloso, linea mediana longitudinali elevata laevi, utrumque latus versus striga transversa abbreviata profunde impressa, basi bisinuato. Scutello minore, densissime piloso; elytris irregulariter lineato-punctatis, interstitiis planis, pilis flavo-auratis longioribus in floccos coactis ornatis; declivitate interstitiis secundo quarto et sexto impressis, tertio et nono apice confluentibus. Subtus aequaliter breviter pilosus et punctatus.

Long. $9 \mathrm{~mm}$, Lat. $4,5 \mathrm{~mm}$. - Patria: Nor d-K a mer un, Johann-Albrechtshöhe. Conradt leg. 1. XI. 1896. Kgl. Zoolog. Museum Berlin.

Das schöne Tier zeichnet sich vor seinen Verwandten durch dichte flockige Behaarung mit starken goldgelben, borstenartigen Haaren aus. In seinen Mundteilen bietet es keine Unterschiede von den in Sumatra lebenden Verwandten (cf. Fig. 1). 
2. Hapalogenius n. gen. Hylesininarum.

Caput subglobosum, insertum, in rostellum haud productum. Labium oblongum, a medio versus apicem abrupte dilatatum, lateribus sinuatis. Ligula latet. Palporum labialium articulus primus maximus, crassus, secundus et tertius simplices, fere aequales. Maxillae lobo securiformi, apice acuminato, intus spinis rigidis ciliato. Palporum maxillarium articulus tertius longissimus, cylindricus, primus et secundus minores, simplices, aequales. Oculi elongati intus emarginati. Antennae funiculo septem-articulato, articulo primo crasso bulbiformi, secundo, tertio, quarto, quinto conicis fere aequalibus, sexto et septimo transversis, capitulo oblongo-ovali, suturis duabus convexis et vittis saetarum compluribus annulato. Prosternum processu nullo. Coxae late distantes. Tibiae extus rotundatae spinosae. Tarsorum articuli primus et secundus aequales, tertius bilobus.

\section{H. globosus n. sp.}

Brevissime ovatus, fere globosus, niger, antennis tarsisque ferrugineis, squamis flavescentibus dense adspersus; fronte in

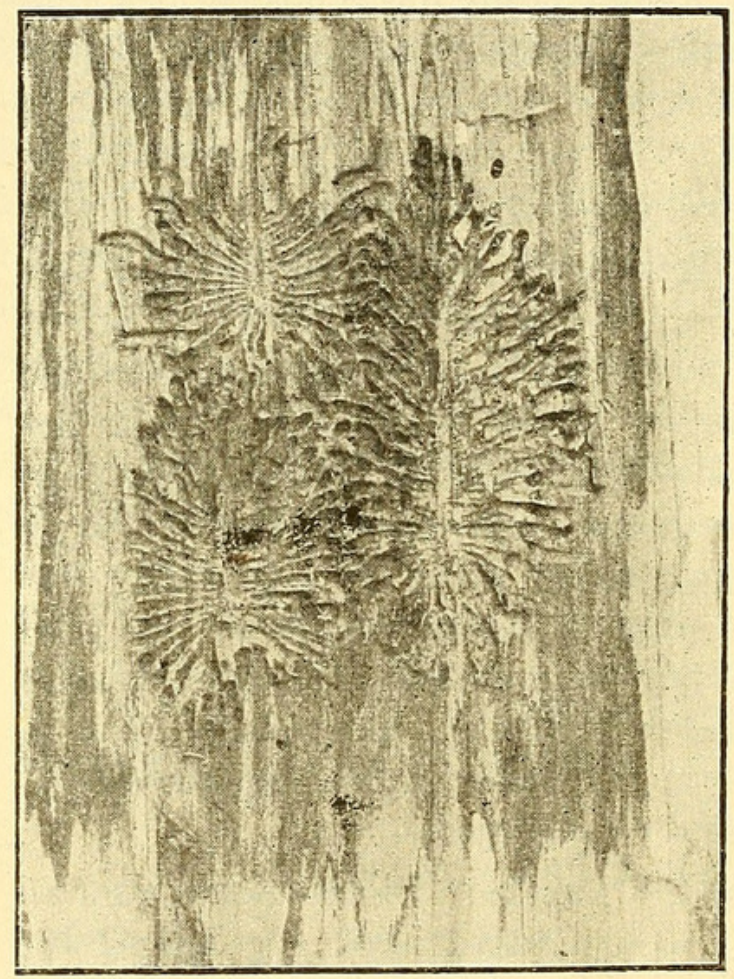

Fig. $2 g$. altero sexu explanata squamisque ciliata, in altero convexa; prothorace transverso, anterius angustato, basi marginato et bisinuato, supra squamoso, linea mediana laevi ornato; elytris striato-punctatis, interstitiis singulis tribus seriebus setarum, mediana maiorum et latiorum, lateralibus minorum flavescentium notatis.

Long. 1,5 $\mathrm{mm}$, Lat. $1 \mathrm{~mm}$. - Patria: PondoLand, im Ecosawald von Dr. Bachmann als Bewohner des „Umzimbiti“-Baumes gesammelt (Kgl. Zoolog. Museum).

Der Liebenswürdigkeit des Herrn Prof. H. K o l b e vom Kgl. Zoolog. Museum in Berlin verdanke ich die Zusendung einiger Frafsstücke, so dafs es mir möglich ist, auch die Beschreibung der Wohnung des Tieres zu geben. Der Muttergang verläuft in der Längsrichtung 
des Baumes in der Länge von $1-2 \mathrm{~cm}$ und der Breite von $1 \mathrm{~mm}$. Er hat einen etwas verbreiterten Eingang und furcht scharf Rinde und Splint. Die Eiernischen stehen dicht beieinander, die Larvengänge verlaufen rechtwinklig vom Muttergang abgehend $1-1 \frac{1}{2} \mathrm{~cm}$ lang sich fächerförmig nach den Enden des Mutterganges neigend; die Puppenwiegen liegen parallel der Längsachse des Baumes in der Rinde (cf. Fig. 2).

\section{Xestips n. gen. Ipinarum.}

Caput globosum receptum; labium oblongum seu oblongotriquetrum, apice alatum, basin versus angustatum, lateribus sinuatis, apice truncato; ligula ovata pilis rigidis longioribus densius adspersa, apice inserta. Palpi labiales articulis longitudine aequalibus, latitudine primo et secundo aequalibus, tertio angustiore conico. Maxillae mala magna antrorsum angustata, posterius fortiter rotundata, anterius sinuata, spinis duodecim ad quindecim compressis ciliata; palporum maxillarium articuli primus et secundus aequales longitudine latiores, tertius conicus longior. Antennae funiculo quinque-articulato, articulo primo crasso globoso, secundo multo minore obconico, sequentibus transversis latitudine sensim crescentibus, capitulo ovali compresso, basi corneo, apice spongioso, suturis duabus semicircularibus ornato. Clava non tunicata. Oculi oblongo-ovales antice sinuati.

Frons perpendiculariter declivis. Thorax cylindricus aequaliter punctatus immarginatus. Elytra cylindrica, stria suturali impressa, declivitate plana retusa. Prosternum processu distincto, coxae approximatae, tibiae angustae apicem versus sensim dilatatae, subrectae, extus spinuloso-dentatae, apice oblique truncatae. Tarsi aequales. Corpus cylindricum.

\section{Xestips marginatus n. sp.}

Cylindricus, niger, nitidus, antennis tarsisque dilutioribus, fronte perpendiculariter declivi rugose-punctato et pilis auronitentibus longioribus ciliato. Thorace aequaliter punctato, supra linea mediana ornato, antice piloso. Elytris cylindricis punctatostriatis, stria suturali impressa, interstitiis muticis sutura elevata, stria tertia tota granulata, quinta et septima solum in declivitate. Declivitate apicali orbiculari plane retusa, ambitu subacute determinata, sutura elevata et tuberculis notata.

Long. 3,3 mm. Patria: O st - A frik a, Deutsches Entomolog. Museum Berlin-Dahlem.

Das interessante Tier, welches sich durch die steil abfallende Stirn vor seinen Verwandten auszeichnet, gehört wegen der kon- 
zentrischen Fühlerkeulennähte, des Baues der Mundteile und der Fülse in die Nähe der Gattung Taphrorychus Eichh. Die gleichmälsige Skulptur des Thorax erinnert etwas an Dryocoetes (cf. Fig. 3).

\section{Trigonogenius n. gen. Ipinarum.}

Caput globosum insertum. Labium triangulare, basin versus angustatum, apice truncatum; ligula linearis, apice truncata et pilis rigidis ciliata, medio labio inserta. Palpi labiales articulo primo maiore, secundo subtransverso, tertio conico parvo. Maxillae mala apice acuminata flexuosa, intus spinulis rigidis rectis ciliata. Palporum maxillarium articulus primus maximus, cylindricus, secundus minimus transversus, tertius longior, conicus. Oculi antice emarginati. Antennarum funiculus quinque-articulatus, articulus primus magnus bulbiformis, sequentes multo minores transversi, latitudine fere aequales, clava ovalis funiculo maior suturis duabus utraque parte aequalibus notata. Prosternum processu nullo. Coxae anticae sese tangentes. Tibiae lineares apice truncatae extus parce spinulosae, angulo interno spina maiore ornatae. Tarsi haud recepti, articulis $1-3$ aequalibus. Prothorax basi marginatus.

\section{Tr. fallax n. sp.}

Elongatus, fuscus seu brunneus, nitidus, parce pilosus, antennis pedibusque testaceis, thorace parvo ovato, antrorsum angustato, antice tuberculis concentricis ornato, postice subtiliter punctato, elytris longis cylindricis subtiliter lineato-punctatis, interstitiis planis muticis, stria suturali impressa, apice rotundatodeclivi, utrinque sulcato, sutura elevata, fundo laevi, ambitu tuberculis minoribus et saetis sparsim notato.

Long. 1,3 mm. - Patria: Amani, Deutsch-Osta frika.

Dem eifrigen Sammler und Erforscher der deutsch-ostafrikanischen Schädlinge Herrn Dr. Morstatt in A mani verdanke ich nicht nur die Übersendung dieses Tieres, welches der Gattung Pityophthorus Eichh. am nächsten steht, sondern auch seiner Wohngänge in Khaja senegalensis. Sein Gangsystem ist ein Sterngang mit ziemlich grofser, tief den Splint furchender Rammelkammer, von welcher mehrere, 3-5, Muttergänge verlaufen, die ebenfalls den Splint tief furchen und mit zahlreichen, nicht sehr dicht beieinander stehenden Einischen besetzt sind. Die Larvengänge, welche das Bestreben haben, der Längsachse des Baumes parallel zu verlaufen, sind kurz, ganz erheblich kürzer als die Muttergänge. Das ganze Frafsbild erinnert etwas an das von Pityophthorus micrographus. 


\section{Allarthrum n. gen. Hylocurinarum.}

Caput globosum, exsertum, sed non rostratum. Oculi antice marginati. Antennae funiculo quadriarticulato quam clava breviore, articulo primo bulbiformi, secundo et quarto transversis aequalibus, tertio minore, clava ovali suturis tribus obsoletis convexis notata. Labium oblongum basi angustatum, apice truncatum; ligula parva ovalis. Palpi labiales articulis primo et secundo aequalibus, tertio minimo conico; maxillae mala securiformi acuminata, spinis rigidis compressis ciliata. Palpi maxillares articulo primo et secundo brevibus simplicibus aequalibus, tertio longiore. Thorax lateribus et basi marginatus. Prosternum processu acuto; coxae distantes. Tibiae lineares, anteriores truncatae, angulo interno unidentato, externo bidentato, extus spinulosae, posteriores extus rotundatae serratae. Tarsorum articulus primus parvus conicus, secundus cylindricus longissimus, tertius cordatus.

\section{A. Kolbei n. sp.}

Oblongo-ovalis, convexus, subnitidus, flavo-brunneus, pilosus, thorace breviter subovato, dorso valde convexo, irregulariter subtilissime punctato et longius piloso; elytris convexis, subtilissime lineato-punctatis, interstitiis irregulariter subtilissime punctatis et uniseriatim parce pilosis.

Long. 1,5 mm. - Patria: Peter hafen, De ut s c h- Ne uguinea. Kgl. Zoolog. Museum Berlin.

Die Gattung ist schwierig unterzubringen. Sie gehört keinesfalls in die Tribus Hylesininae und Ipinae; ebensowenig kann man sie bei den Eccoptogastrinae einstellen. Am meisten verwandt dürfte sie noch mit Pycnarthrum Eichh. sein. Deshalb will ich sie vorläufig zu den Hylocurinen stellen, behalte mir aber vor, wenn weitere Untersuchungen gröfseren Materials bestimmitere Anhaltspunkte gewähren, für sie eine eigene Tribus zu gründen. Herrn Prof. Kolbe, welchem ich das Tier verdanke, sei dasselbe als Zeichen meiner Hochachtung gewidmet (cf. Fig. 5).

\section{Cyclorhipidion n. gen. Xyleborinarum.}

Caput globosum receptum. Labium oblongum angustum, apice dilatatum et truncatum, lateribus rectis, ligula parva ovalis infra apicem labii inserta, pilis rigidis permultis ornata. Palpi labiales articulo primo maximo tumido, intus villoso-barbato, secundo transverso, tertio conico minoribus. Maxillae mala versus apicem angustata, anterius recta setis subtilibus falcatis in apice densissimis ciliata. Palpi maxillares articulo primo maiore, secundo minore, tertio conico longiore sine lineis longitudinalibus. Antennae funiculo quinque - articulato, articulo primo crasso bulbi- 


\section{$2 \mathrm{BHL}$ Biodiversity Heritage Library}

Hagedorn, Max. 1912. "Neue Borkenkäfergattungen und Arten aus Afrika (Col)." Deutsche entomologische Zeitschrift 1912(3), 351-356.

View This Item Online: https://www.biodiversitylibrary.org/item/103378

Permalink: https://www.biodiversitylibrary.org/partpdf/251166

\section{Holding Institution}

Harvard University, Museum of Comparative Zoology, Ernst Mayr Library

\section{Sponsored by}

Biodiversity Heritage Library

\section{Copyright \& Reuse}

Copyright Status: Public domain. The BHL considers that this work is no longer under copyright protection.

This document was created from content at the Biodiversity Heritage Library, the world's largest open access digital library for biodiversity literature and archives. Visit BHL at https://www.biodiversitylibrary.org. 